\section{(2) OPEN ACCESS}

\title{
Acute transverse myelitis in COVID-19 infection
}

\author{
Chian Chiang Nicholas Chow (D) ,' John Magnussen, ${ }^{1}$ Jerome Ip, ${ }^{1,2}$ Yuen Su (D) ${ }^{1}$
}

${ }^{1}$ Emergency Department, Hornsby Ku-ring-gai Hospital, Sydney, New South Wales, Australia

${ }^{2}$ Sydney Adventist Hospital Ltd, Sydney, New South Wales, Australia

\section{Correspondence to} Dr Chian Chiang Nicholas Chow:

chow.nicholas@gmail.com

Accepted 22 July 2020

Check for updates

(C) BMJ Publishing Group Limited 2020. Re-use permitted under CC BY-NC. No commercial re-use. See rights and permissions. Published by BMJ.

To cite: Chow CCN,

Magnussen J, Ip J, et al. BMJ

Case Rep 2020;13:e236720.

doi:10.1136/bcr-2020-

236720

\section{SUMMARY}

A 60-year-old man presented to hospital with bilateral lower limb weakness, urinary retention and constipation. He had been diagnosed with COVID-19 10 days prior. Clinical examination revealed global weakness, increased tone, hyperreflexia and patchy paresthesia in his lower limbs bilaterally. Preliminary blood tests performed revealed a mildly elevated $C$ reactive protein and erythrocyte sedimentation rate but was otherwise unremarkable. MRI scan of his whole spine demonstrated hyperintense $T 2$ signal centrally from T7 to T10, suggestive of acute transverse myelitis. A lumbar puncture showed elevated protein count but normal glucose and white blood cell count. Serological testing for other viruses was negative. His neurological symptoms improved significantly after treatment with intravenous methylprednisone. This case highlights a potential neurological complication of COVID-19 infection.

\section{BACKGROUND}

There is growing evidence to support the potential for central nervous system (CNS) involvement in the context of acute and post-COVID-19 infection..$^{1-3}$ It is important to recognise potential neurological manifestations and complications of COVID19 , some of which can be rapidly progressing and require urgent intervention.

\section{CASE PRESENTATION}

A 60-year-old man presented to hospital with progressive bilateral lower limb weakness, urinary retention and constipation.

Eighteen days prior, he developed fever and cough 1 day after returning from a flight from South America. His symptoms persisted, and he also developed loss of taste (dysgeusia) and smell (anosmia). A nasopharyngeal swab for SARS-CoV-2 PCR was positive (AusDiagnostics) on day 7 of his illness. He did not receive any specific treatment (antiviral or immune modulatory) for COVID-19. His respiratory symptoms resolved after 13 days. On day 16 , he developed acute urinary retention and required insertion of a bladder catheter. Over the next 2 days, he reported progressive lower limb stiffness, difficulty walking and constipation, prompting his visit to the emergency department.

His medical history included well-controlled hypertension and hypercholesterolaemia for which he takes an angiotensin receptor blocker/calcium channel blocker and a statin, respectively. He was an ex-smoker and worked for the aviation industry. $\mathrm{He}$ had been involved in repatriation flights from South
America to Australia. Several of his colleagues were also diagnosed with COVID-19 after returning on the same flight.

On presentation to the emergency department, the patient was noted to have normal observations and was afebrile. His respiratory rate was 16 breaths per minute, oxygen saturation of $97 \%$ on room air, blood pressure of $154 / 88(110) \mathrm{mm} \mathrm{Hg}$, heart rate of 85 beats per minute and temperature of $36.7^{\circ} \mathrm{C}$. Clinical examination revealed increased tone, hyperreflexia and reduced proprioception of the lower limbs. The patient also exhibited patchy paresthesia bilaterally to the level of the umbilicus. There was decreased anal tone on digital rectal examination. There was no clinical evidence of major head or spinal trauma and the remainder of his cranial nerve and general neurological examination was unremarkable. These findings were consistent with an upper motor neuron lesion. The patient was admitted to hospital for further evaluation and treatment.

\section{INVESTIGATIONS}

Preliminary blood tests revealed a mildly elevated $\mathrm{C}$ reactive protein $(\mathrm{CRP})(21 \mathrm{mg} / \mathrm{L})$, elevated erythrocyte sedimentation rate $(44 \mathrm{~mm} /$ hour $)$, elevated D-dimer $(0.79 \mathrm{~g} / \mathrm{L})$ and lymphopaenia $\left(0.8 \times 10^{9} / \mathrm{L}\right)$ (table 1).

CT scan with intravenous contrast of his lumbosacral spine showed diffuse disc bulge at L5/S1 with mild thecal sac indentation but no significant central canal stenosis. CT brain with intravenous contrast did not show hydrocephalus, space occupying lesion, oedema or haemorrhage. CT chest showed scattered peripheral areas of ground-glass opacity and consolidation in both lungs (figure 1).

MRI scan of his whole spine demonstrated a long segment of T2 signal elevation centrally in the spinal cord from T7 to T10, without significant enhancement or the presence of a mass (figures 2-3). MRI brain and orbits did not show any indication of recent or ongoing inflammatory change to suggest a relationship to the MRI changes observed in the spine.

Cerebrospinal fluid (CSF) collected from lumbar puncture showed elevated protein count $(0.79 \mathrm{~g} / \mathrm{L})$ but normal glucose $(3.2 \mathrm{mmol} / \mathrm{L})$ (table 1$)$. CSF culture and blood cultures were negative. SARS-CoV-2 (PCR) from nasopharyngeal swab and CSF was not detected. Serology for SARS-CoV-2 demonstrated recent infection (SARS-CoV-2 IgG 640, SARS-CoV-2 IgA 160, SARS-CoV-2 IgM 20 by in-house immunofluorescent antibody testing). ACE levels were not detected in CSF. Antibodies for anti-myelin-associated glycoprotein IgM 


\begin{tabular}{|c|c|}
\hline \multicolumn{2}{|l|}{ Count $\times 10^{12} / L$} \\
\hline White blood cell & $\begin{array}{l}0.0051(0.004- \\
0.011)\end{array}$ \\
\hline Neutrophil & $0.036(0.002-0.008)$ \\
\hline Lymphocyte & $\begin{array}{l}0.0008(0.001- \\
0.004)\end{array}$ \\
\hline Platelet & $0.408(0.150-0.400)$ \\
\hline C reactive protein (mg/L) & $21(<5)$ \\
\hline Erythrocyte sedimentation rate (mm/hour) & $44(1-14)$ \\
\hline D-dimer (mg/L) & $0.7(<0.5)$ \\
\hline Creatine kinase (unit/L) & $53(40-200)$ \\
\hline Lactate dehydrogenase (unit/L) & $226(120-250)$ \\
\hline Alkaline phosphatase (unit/L) & $60(30-110)$ \\
\hline Gamma-glutamyltransferase (unit/L) & $46(5-50)$ \\
\hline Alanine aminotransferase (unit/L) & $49(10-50)$ \\
\hline Aspartate aminotransferase (unit/L) & $22(10-35)$ \\
\hline Blood urea nitrogen (mmol/L) & $4.4(4.0-9.0)$ \\
\hline Creatinine $(\mu / L)$ & $71(60-110)$ \\
\hline \multicolumn{2}{|l|}{ Cerebrospinal fluid microscopy } \\
\hline Glucose (mmol/L) & $3.2(2.8-4.5)$ \\
\hline Protein (g/L) & $0.79(0.19-0.63)$ \\
\hline Lactate dehydrogenase (unit/L) & $<30(<30)$ \\
\hline \multicolumn{2}{|l|}{ Count $\times 10^{12} / L$} \\
\hline Red cell & $<0.001(<0.001)$ \\
\hline Polymorph & $0.006(<0.005)$ \\
\hline Mononuclear & $0.004(<0.005)$ \\
\hline
\end{tabular}

Bold values fall out of the normal range which have been listed in brackets.

(ELISA), myelin oligodendrocyte glycoprotein (in-house assay) and neuromyelitis optica IgG (Euroimmun immunofluoresence) were negative in serum. Serology for mycoplasma, Epstein-Barr virus, cytomegalovirus, $\mathrm{HIV}$, hepatitis $\mathrm{B}$ and $\mathrm{C}$ was negative. An autoimmune panel did not suggest primary autoimmune condition. Serum ferritin $(711 \mu / \mathrm{L})$ and interleukin-6 levels $(7.8 \mathrm{pg} /$ $\mathrm{mL}$ ) were only measured day 10 of admission (28 days after symptom onset) and showed elevated ferritin but normal interleukin-6 (IL-6) level.

\section{DIFFERENTIAL DIAGNOSIS}

The presence of upper motor neuron signs in this patient prompted the need for a detailed neurological examination. He did not report a history to suggest significant head or spinal trauma. The progressive onset of his neurological symptoms made the diagnosis of a cerebrovascular accident less likely. His preliminary blood work and clinical observations did not suggest severe systemic infection. The patient's medical history did not offer any further clues to his presentation. Neuroimaging was not suggestive of demyelinating condition such as multiple sclerosis. Taking into account his recent viral infection (COVID-19), we explored the possibility of post-viral acute transverse myelitis (ATM).

\section{TREATMENT}

The patient was treated with intravenous methylprednisone $1 \mathrm{~g}$ per day for 3 days. He also received intensive physiotherapy during his time in hospital. No antivirals, antibiotics or immune-modulatory drugs were given apart from the methylprednisolone.

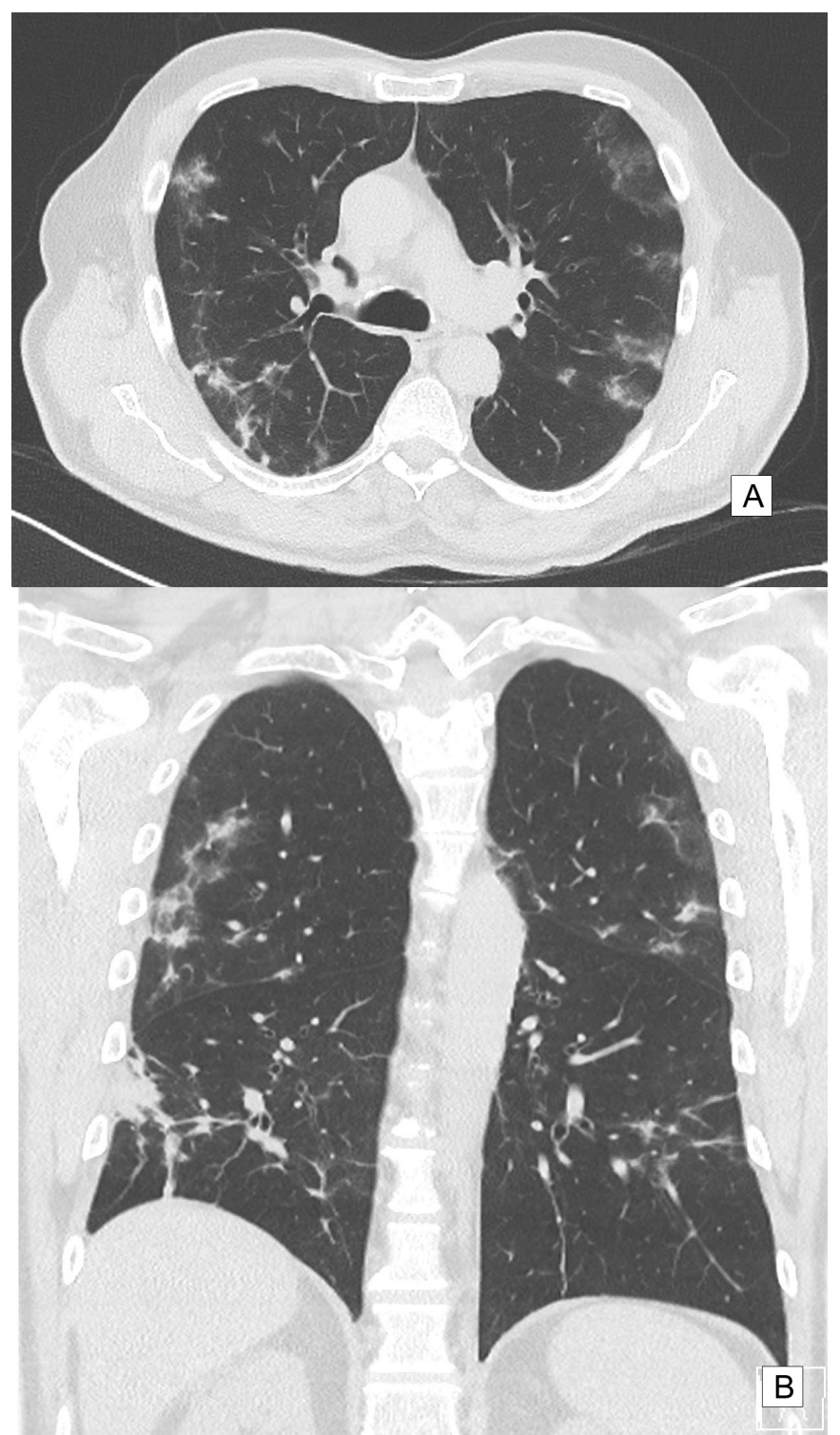

Figure $1 \mathrm{CT}$ imaging of the patient's chest. Non-contrast, (A) axial and (B) coronal slice demonstrating scattered peripheral, multilobular ground-glass opacities and consolidation in both lungs, 18 days after symptom onset.

\section{OUTCOME AND FOLLOW-UP}

Neurological symptoms improved shortly after completion of corticosteroid therapy. MRI whole spine was repeated on day 10 , which showed almost complete resolution of the changes seen previously between T7 and T10. He regained full lower limb motor strength, the paresthesias completely resolved and the indwelling catheter was successfully removed. $\mathrm{He}$ was discharged to home on day 11 of admission.

\section{DISCUSSION}

The most common symptoms associated with COVID-19 infection include fever, cough, fatigue and dyspnoea. ${ }^{4}$ More recent evidence has suggested an increased incidence of anosmia and dysgeusia with COVID-19 infection. ${ }^{2}$ This is thought to arise because SARS-CoV-2 virus may be able to directly invade the nervous system via the olfactory tract or the blood circulation during a proinflammatory state. ${ }^{1-3}$ Viral encephalitis, as another presentation of CNS involvement, has been 


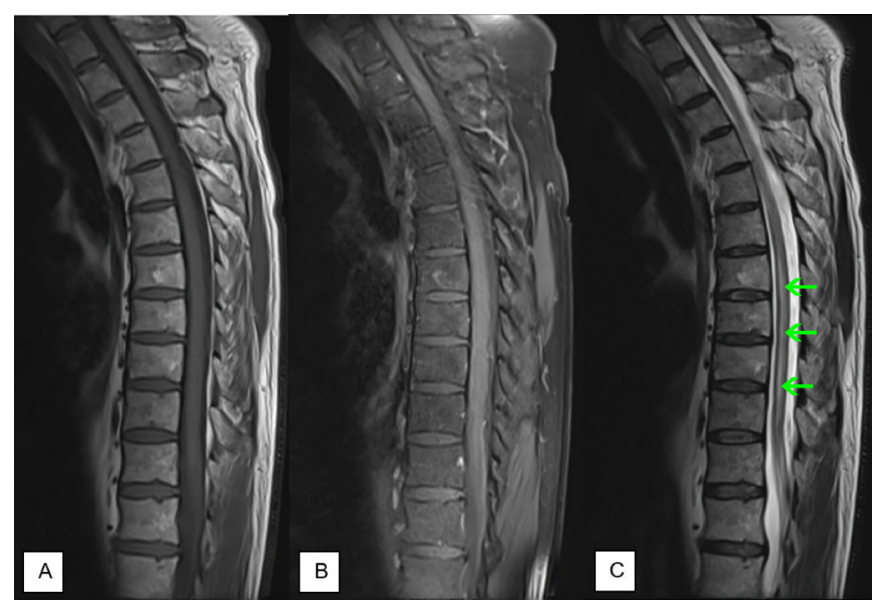

Figure 2 MRI of the patient's thoracic spine. (A) Sagittal T1 sequence of the thoracic spine. (B) Fat-saturated sagittal T1 sequence of the thoracic spine postintravenous gadolinium contrast. (C) Sagittal T2 sequence of the thoracic spine, demonstrating a long segment of $\mathrm{T} 2$ signal elevation centrally in the spinal cord from $\mathrm{T} 7$ to T10. No significant canal stenosis or paravertebral mass was observed.

reported in the context of acute COVID-19 infection. ${ }^{5}$ In this instance, SARS-CoV-2 RNA was detected in CSF and MRI brain-demonstrated findings consistent with meningitis. ${ }^{5}$ Wu et $a l^{2}$ further hypothesise that SARS-CoV-2 may induce neuronal injury via hypoxic and immune-mediated pathways. SARS-CoV-2 binds strongly to ACE2 receptors that have been described in the heart, lungs, CNS and skeletal muscle. ${ }^{12}$ Viral replication and thus increased ACE2 receptor activation in the CNS may trigger a systemic inflammatory response, resulting in increased permeability of the blood-brain barrier and immunemediated inflammation of the CNS. ${ }^{2}$ IL-6, a proinflammatory cytokine, has been thought to mediate this response. ${ }^{6-8}$ Elevated IL-6 level leads to increased acute phase protein production such as CRP and fibrinogen. ${ }^{6}$ IL- 6 has been recently highlighted as a potential predictor of COVID-19 infection severity, progression and mortality. ${ }^{6-8}$ Elevated ferritin levels have also been linked to more severe infection and poorer outcomes. ${ }^{7}$ Unfortunately, IL-6 and ferritin levels were not performed for this patient on admission. Serum ferritin level remained elevated 28 days from symptom onset, but IL-6 level was normal. It is important to note that this was also 4 days post-steroid administration and therefore could potentially reflect amelioration.

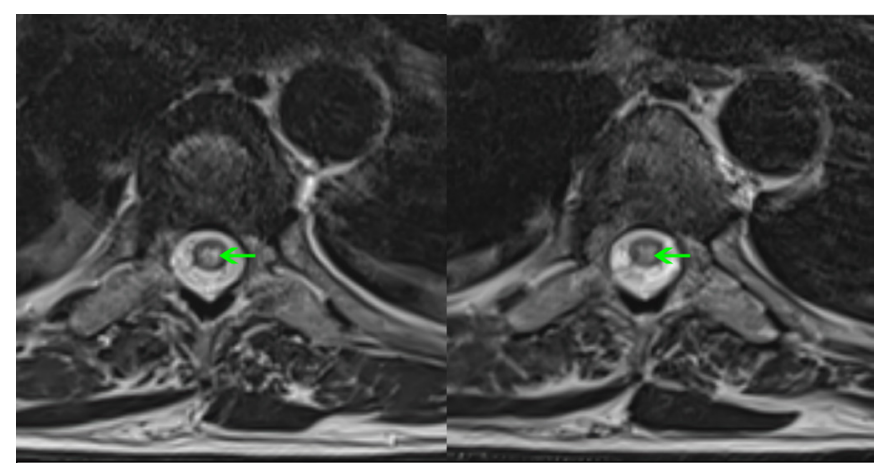

Figure $3 \mathrm{MRI}$ of the patient's thoracic spine. T2 sequence, consecutive axial slices at the level of $\mathrm{T7}$ demonstrating signal elevation centrally in the spinal cord.

\section{Patient's perspective}

I did not expect to contract COVID-19. I used to think that this virus only affected the lungs. When I had trouble going to the toilet, I thought I could have cancer. The next couple of days that followed were scary. I could not understand what was happening to my body. When I came into hospital, I struggled to understand my diagnosis but was relieved that I did not require an operation. The medication they gave me helped and my symptoms improved quickly. People need to know that COVID-19 can affect other organs as well.

\section{Learning points}

- Neurological complications may occur in the context of COVID-19 infection.

- Consider MRI scan when investigating upper neuron syndrome.

- Corticosteroid therapy in acute transverse myelitis can rapidly improve neurological symptoms.

We have presented a case of ATM in the context of recent COVID-19 infection. We did not detect SARS-CoV-2 RNA in the CSF and postulate that this presentation was likely due to an immune-mediated inflammatory process rather than direct invasion of SARS-CoV-2 into the CNS. A review of the literature revealed one similar case report of myelitis post-COVID-19 infection but did not include MRI or CSF analysis. ${ }^{9}$

Acknowledgements We thank Dr Charles Lawrie (Hornsby Ku-ring-gai Hospital) for his support during the writing of this case report.

Contributors Conception and planning of case report as well as obtaining patient consent was performed by CCNC. CCNC has also written the majority of the manuscript, data acquisiation and interpretation. JM provided MRI images and their interpretation. Jl and YS reviewed the manuscript and contributed towards the final draft submitted.

Funding The authors have not declared a specific grant for this research from any funding agency in the public, commercial or not-for-profit sectors.

Competing interests None declared.

Patient consent for publication Obtained.

Provenance and peer review Not commissioned; externally peer reviewed.

Open access This is an open access article distributed in accordance with the Creative Commons Attribution Non Commercial (CC BY-NC 4.0) license, which permits others to distribute, remix, adapt, build upon this work non-commercially, and license their derivative works on different terms, provided the original work is properly cited and the use is non-commercial. See: http://creativecommons.org/ licenses/by-nc/4.0/.

\section{ORCID iDs}

Chian Chiang Nicholas Chow http://orcid.org/0000-0003-4937-2553

Yuen Su http://orcid.org/0000-0001-9726-3664

\section{REFERENCES}

1 Mao L, Jin H, Wang M, et al. Neurologic manifestations of hospitalized patients with coronavirus disease 2019 in Wuhan, China. JAMA Neurol 2020;77:683-90.

2 Wu Y, Xu X, Chen Z, et al. Nervous system involvement after infection with COVID-19 and other coronaviruses. Brain Behav Immun 2020;87:18-22.

3 Asadi-Pooya AA, Simani L. Central nervous system manifestations of COVID-19: a systematic review. J Neurol Sci 2020;413:116832.

4 Phua J, Weng L, Ling L, et al. Intensive care management of coronavirus disease 2019 (COVID-19): challenges and recommendations. Lancet Respir Med 2020:8:506-17.

5 Moriguchi T, Harii N, Goto J, et al. A first case of meningitis/encephalitis associated with SARS-Coronavirus-2. Int J Infect Dis 2020;94:55-8. 


\section{Findings that shed new light on the possible pathogenesis of a disease or an adverse effect}

6 Zhu Z, Cai T, Fan L, et al. Clinical value of immune-inflammatory parameters to assess the severity of coronavirus disease 2019. Int J Infect Dis 2020;95:332-9.

7 Zhou F, Yu T, Du R, et al. Clinical course and risk factors for mortality of adult inpatients with COVID-19 in Wuhan, China: a retrospective cohort study. Lancet 2020;395:1054-62
8 Ruan Q, Yang K, Wang W, et al. Clinical predictors of mortality due to COVID-19 based on an analysis of data of 150 patients from Wuhan, China. Intensive Care Med 2020;46:846-8.

9 Zhao K, Huang J, Dai D, et al. Acute myelitis after SARS-CoV-2 infection: a case report. medRxiv 2020;2020

Copyright 2020 BMJ Publishing Group. All rights reserved. For permission to reuse any of this content visit https://www.bmj.com/company/products-services/rights-and-licensing/permissions/

BMJ Case Report Fellows may re-use this article for personal use and teaching without any further permission.

Become a Fellow of BMJ Case Reports today and you can:

- Submit as many cases as you like

Enjoy fast sympathetic peer review and rapid publication of accepted articles

- Access all the published articles

Re-use any of the published material for personal use and teaching without further permission

Customer Service

If you have any further queries about your subscription, please contact our customer services team on +44 (0) 2071111105 or via email at support@bmj.com.

Visit casereports.bmj.com for more articles like this and to become a Fellow 